\title{
Efeito terapêutico da aplicação intra-ocular de ozônio em modelo experimental de endof talmite por Staphylococcus epidermidis em coelhos
}

\author{
Therapeutic effect of in traocular application of ozone in experimentalstaphylococcus \\ epidermidis endophthalmitis
}

\author{
Jonathan Clive Lake ${ }^{1}$ \\ Sergio Felberg'1 \\ Gustavo Ricci Malavazzi ${ }^{2}$ \\ Denise Atique Goulart ${ }^{3}$ \\ Maria Cristina Nishiwaki-Dantas ${ }^{4}$ \\ Paulo Elias Correa Dantas ${ }^{4}$
}

Santa Casa de Misericórdia de São Paulo - Departamento de Oftalmologia - Rua Cesário Mota Júnior, 112 CEP 01221906 - São Paulo (SP)

${ }^{1}$ Assistente da Seção de Córnea e Doenças Externas do Departamento de Oftalmologia da Santa Casa de São Paulo.

2 Instrutor do Instituto da Catarata da Escola Paulista de Medicina - Universidade Federal de São Paulo.

3 Pós graduanda do Departamento de Oftalmologia da Universidade Federal de São Paulo.

${ }^{4}$ Chefe da Seção de Córnea e Doenças Externas do Departamento de Oftalmologia da Santa Casa de São Paulo.

Endereço para correspondência: Jonathan Clive Lake Av. José Galante 811, apt. 181 - São Paulo (SP)

CEP 05642-001

E-mail: jlake@uol.com.br

Recebido para publicação em 02.07.2003

Versão revisada recebida em 20.10.2003

Aprovação em 20.01.2004

\begin{tabular}{|c|}
\hline RESUMO \\
\hline $\begin{array}{l}\text { Objetivo: Avaliar a ação antiinflamatória e antimicrobiana da injeção } \\
\text { intravítrea de ozônio diluído em solução salina balanceada (BSS) em } \\
\text { modelo experimental de endoftalmite por Staphylococcus epidermidis. } \\
\text { Métodos: Dezessete coelhos da raça Nova Zelândia receberam inoculação } \\
\text { no olho direito de } 0,1 \text { ml de uma solução de } 10^{5} \text { bactérias ( } \text { S. epidermidis) } \\
\text { por ml para indução de endoftalmite. Sete coelhos receberam injeção } \\
\text { intravítrea de } 0,1 \text { ml de BSS como controle e os outros dez coelhos re- } \\
\text { ceberam injeção intravítrea de } 0,1 \text { ml de BSS com ozônio diluído a } 2 \text { ppm. } \\
\text { Os dados foram quantificados de acordo com parâmetros clínicos e } \\
\text { histopatológicos e computados numericamente para cada coelho após } 24 \\
\text { horas de evolução. As médias e os desvios-padrão (DP) foram calculados } \\
\text { e comparados por meio de teste } t \text { com duas amostras. Resultados: A média } \\
\text { da quantificação clínica dos olhos dos coelhos do grupo controle foi de } \\
\text { 11,14 com DP de } 1,04 \text {. A média clínica dos olhos tratados com ozônio foi } \\
\text { de } 4,90 \text { com DP de } 1,29 \text {. A média dos olhos tratados com ozônio foi sig- } \\
\text { nificativamente menor do que os não tratados (P<0,01). A média da } \\
\text { quantificação histopatológica dos olhos dos coelhos do grupo controle } \\
\text { e do grupo tratado com ozônio foi de } 17,00 \text { (DP=0,57) e de } 10,20 \text { (DP=1,30), } \\
\text { respectivamente. A resposta inflamatória do grupo tratado foi significativa- } \\
\text { mentemenor do que o não tratado (P<0,01). Conclusão: O ozônio diminuiu } \\
\text { significativamente a reação inflamatória no modelo de endoftalmite pes- } \\
\text { quisado. Isto ocorreu possivelmente devido à redução da carga bacteriana } \\
\text { provocado pelo ozônio. Ainda é necessário estudar vias de administração } \\
\text { e concentrações de ozônio mais eficazes em outros modelos de infecção. }\end{array}$ \\
\hline
\end{tabular}

Descritores: Ozônio/uso terapêutico; Endoftalmite/induzido quimicamente; Staphylococcus epidermidis; Solução salina hipertônica; Soluções oftálmicas; Coelhos

\section{INTRODUÇÃO}

A endoftalmite bacteriana (EB) é doença grave, que tem potencial destrutivo para os componentes estruturais do olho. A EB caracteriza-se por intensa resposta inflamatória necrosante que pode afetar todos os componentes do segmento posterior e anterior. Sua causa está relacionada à entrada de agentes infecciosos após procedimentos cirúrgicos intra-oculares e ferimentos decorrentes de traumatismos penetrantes ${ }^{(1-2)}$.

O tratamento da endoftalmite é dificultado pela cobertura do amplo espectro de agentes infecciosos mais comuns (Staphylococcus epidermidis, 
576 Efeito terapêutico da aplicação intra-ocular de ozônio em modelo experimental de endoftalmite por

Staphylococcus epidermidis em coelhos

Staphylococcus aureus, Streptococcus pneumoniae, Haemophilus influenzae e Propionibacterium acnes) ${ }^{(1-3)}$ e à baixa penetração farmacológica através da barreira hematológica do olho $^{(1,3)}$. Sua incidência varia de 0,08 a $0,4 \%$, e ocorre com maior freqüência após procedimentos cirúrgicos $(70 \%)^{(2-5)}$. Seu tratamento depende de diagnóstico preciso e precoce e oferece diferentes abordagens que visam a eliminação da bactéria e a diminuição da reação inflamatória desencadeada pela infecção. As opções de tratamento atualmente são a utilização de combinações de antimicrobianos de amplo espectro administrados por várias vias associados com corticóides ou vitrectomia terapêutica ${ }^{(6)}$. A escolha de um destes métodos é controverso, já que seus resultados são muito variáveis devido à virulência dos organismos e à resposta individual ao tratamento. A escolha de terapia mais agressiva, em alguns casos, não é suficiente para impedir o processo de destruição celular do olho ${ }^{(5-6)}$.

Ozônio é utilizado para esterilização de materiais em grande volume de forma eficaz. Sua utilização na esterilização de água e cerveja, além de materiais utilizados para embalagem alimentícia, é reconhecida devido à sua eficácia contra agentes microbianos e por não deixar resíduos tóxicos após sua decomposição(7-8). Seu mecanismo de ação antimicrobiano ocorre por lise da membrana dos agentes após oxidação. O aspecto biomédico do ozônio não foi amplamente discutido pela pequena quantidade de referências bibliográficas do assunto e pela falta de estudos amplos e controlados. Os relatos sobre terapia com ozônio na literatura limitam-se a trabalhos e experiências isoladas, que não apresentam resultados controlados rigorosamente $\mathrm{e}^{(9-10)}$. Aplicação do ozônio como forma terapêutica viável tem sido retomada em estudos recentes como hemoterapia ${ }^{(8)}$. Estas pesquisas atribuem outras qualidades ao ozônio, tais como: estímulo à produção de citoquinas, síntese de anticorpos, ativação de linfócitos T, melhora da oxigenação e do metabolismo celular por meio de vasodilatação e do aumento da resposta enzimática antioxidativa ${ }^{(7)}$.

Sobre o tratamento de endoftalmite infecciosa, dois estu$\operatorname{dos}^{(9-10)}$ ressaltam possível melhora da resposta inflamatória. Um estudo $^{(9)}$ experimental animal com injeções intra-oculares de ozônio encontrou melhora da inflamação. Outro estudo(10) compara um grupo de 27 pacientes com endoftalmite tratados com vitrectomia utilizando solução salina ozonizada com um grupo controle de 28 pacientes com endoftalmite tratados com vitrectomia utilizando gentamicina. Os dois grupos apresentaram evoluções semelhantes.

Com a determinação recente de concentração sanguínea terapêutica e o desenvolvimento de sistema de administração $\operatorname{direta}^{(8)}$, a terapia com ozônio nas endoftalmites bacterianas pode ser alternativa viável e eficaz, tanto na destruição do agente quanto na melhora da reação inflamatória, sem causar destruição tecidual.

O presente estudo teve como objetivo avaliar o efeito terapêutico e os resultados da administração intravítrea de ozônio, diluído em solução salina balanceada, em modelo experimental de endoftalmite por Staphylococcus epidermidis em coelhos, analisando parâmetros clínicos e histopatológicos como resultados terapêuticos.

\section{MÉTODOS}

\section{Seleção e manutenção dos animais de experimentação}

Dezessete coelhos albinos da raça Nova Zelândia, com peso de 2 a $3 \mathrm{~kg}$, foram selecionados. Sete deles foram utilizados como grupo controle do modelo de endoftalmite com injeção intravítrea de BSS e outros dez para tratamento com injeção intravítrea de ozônio diluído em BSS. Os animais foram mantidos na Unidade de Técnica Cirúrgica e Cirurgia Experimental (UTECE)/Santa Casa de São Paulo, em gaiolas individuais, com suporte hídrico-alimentar mantido e controlado diariamente. Não foi constatado sinal de infecção prévia nos animais estudados. O manuseio dos animais de experimentação seguiu as normas e orientações do Comitê Brasileiro de Estudos em Animais de Experimentação (COBEA), da Association for Research in Ophthalmology (ARVO) e da UTECE/ Santa Casa.

\section{Seleção do agente bacteriano e preparo do inóculo}

A partir de cepa de Staphylococcus epidermidis, disponível no Departamento de Microbiologia da Santa Casa de São Paulo, solução de 0,1 ml foi preparada com concentração de $10^{5}$ células por mililitro, obtida por turvação.

\section{Técnica da injeção intravítrea}

Os coelhos foram anestesiados com dose intramuscular de $1 \mathrm{ml}$ de mistura 1:1 de ketamina $(100 \mathrm{mg} / \mathrm{ml})$ e xilazina $(20 \mathrm{mg} / \mathrm{ml})$ antes da inoculação do agente bacteriano. Colírio de proparacaína a $0,5 \%$ foi usado para anestesia tópica. Midríase foi obtida e mantida com o uso de colírio de atropina durante o experimento.

O modelo experimental de endoftalmite foi descrito por Meredith e cols. ${ }^{(2)}$. Foi realizada injeção de $0,1 \mathrm{ml}$ da suspensão de $S$. epidermidis $\left(10^{5}\right.$ cels $\left./ \mathrm{ml}\right)$ nos olhos direitos dos coelhos do grupo controle via pars plana, a $2 \mathrm{~mm}$ do limbo, direcionada ao meio do humor vítreo. Paracentese da câmara anterior $(0,1 \mathrm{ml})$ foi realizada antes da injeção no humor vítreo com agulha e seringa de insulina estéreis. Imediatamente após a injeção de $S$. epidermidis foi injetado pela pars plana $0,1 \mathrm{ml}$ de BSS. Foram colhidos dados clínicos a partir de observador independente e mascarado, que preencheu formulário de dados 24 horas após a inoculação. Após exame clínico, foi realizada punção do humor vítreo para cultura. O coelho em seguida foi sacrificado com $5 \mathrm{ml}$ de tiopentato sódico (Thionembutal $^{\circledR}$ ) intra-cardíaco $(40 \mathrm{mg} / \mathrm{ml})$ e o olho foi enucleado. O exame anátomo-patológico também foi realizado por observador independente, seguindo formulário de dados padronizado.

\section{Preparo e técnica da ozonioterapia intravítrea}

O ozônio foi gerado a partir de descarga elétrica em átomos de oxigênio em aparelho fornecido pela Ozonetechnik (São 
Paulo, Brasil), desenvolvido especialmente para este experimento. O ozônio foi diluído na proporção de 2 partes por milhão (ppm) em solução salina balanceada. Imediatamente após a injeção de $S$. epidermidis, $0,1 \mathrm{ml}$ da solução ozonizada foi injetada nos olhos direitos dos coelhos.

Após um dia, os coelhos foram examinados por observador independente, que preencheu formulário específico de dados e realizou coleta de humor vítreo para cultura. Os coelhos em seguida foram sacrificados da forma previamente descrita, e seus olhos enucleados para estudo anatomopatológico por observador independente e mascarado.

\section{Análise dos dados}

A avaliação clínica de cada olho seguiu modelo proposto por Park e cols. ${ }^{(2)}$. Quatro estruturas do olho foram examinadas e o grau de inflamação foi avaliada da seguinte forma:

\section{Conjuntiva \\ - normal; \\ - edema leve; \\ - edema e hiperemia moderada; \\ - edema e hiperemia grave.}

\section{Córnea}

- clara;

- edema focal;

- edema difuso;

- opaca.

\section{Íris}

- normal;

- hiperemia leve;

- hiperemia acentuada;

- sinéquias, corectopia.

\section{Vítreo}

- claro;

- reflexo bom com "haze";

- "haze" moderado;

- sem reflexo vermelho.

O exame histopatológico avaliou a presença ou não de inflamação aguda, e dividiu de acordo com o grau de acometimento em: sem inflamação, inflamação leve, inflamação moderada e inflamação grave. As estruturas avaliadas foram córnea, íris, corpo ciliar, coróide, vítreo e retina.

Tanto na avaliação clínica quanto na histopatológica cada avaliação recebeu pontos que foram atribuídos da seguinte maneira, seguindo a ordem de caracterização descrita acima:

- zero pontos para estruturas não acometidas;

- um ponto para acometimentos leves;

- dois pontos para acometimentos moderados;

- três pontos para acometimentos graves.

O total de pontos possíveis na avaliação clínica foi 12. O total possível na quantificação histopatológica foi 18.

Para cada coelho foi realizada soma dos pontos, resultan- do em uma nota final. A média e o desvio padrão foram calculados para as notas do grupo controle e do grupo que recebeu ozonioterapia. As amostras foram comparadas pelo teste $t$ de duas amostras com nível de significância de 1\%, utilizando o programa de estatística Minitab ${ }^{\circledR}$ versão 12 para Windows 95.

\section{RESULTADOS}

Os resultados da observação clínica e sua quantificação podem ser observados no quadro 1 . Todos os olhos do grupo controle e do grupo que recebeu terapia com ozônio mostraram reação inflamatória um dia após a inoculação. Todos os olhos estudados apresentaram culturas positivas para $S$. epidermidis na punção vítrea realizada após 24 horas.

O grupo controle apresentou intensa reação corneal: 4 (57\%) olhos com córneas opacas e 3 (43\%) com edema difuso. Em nenhum animal foi possível observar os detalhes da retina ou vítreo. Os detalhes da íris foram de difícil observação.

No grupo tratado com ozônio diluído em solução salina balanceada foram observados $8(80 \%)$ olhos com córneas claras e 2 (20\%) que apresentaram edema difuso. A íris pôde ser observada com maiores detalhes; observou-se discreta reação inflamatória em oito olhos (80\%) e reação moderada em 2 olhos (20\%). Não foi possível observar a retina nos dez (100\%) olhos tratados devido à opacidade dos meios. Em um olho foi possível observar opacificação moderada, que não permitiu observação da retina.

A graduação dos sinais clínicos dos olhos do grupo controle pode ser observada no quadro 1 . A média dos parâmetros clínicos analisados neste grupo de 11,14 $\pm 1,04$. Porém nos

\begin{tabular}{|c|c|}
\hline \multicolumn{2}{|c|}{ Grupo controle: } \\
\hline Coelho 1 & 12 \\
\hline Coelho 2 & 12 \\
\hline Coelho 3 & 12 \\
\hline Coelho 4 & 10 \\
\hline Coelho 5 & 10 \\
\hline Coelho 6 & 10 \\
\hline Coelho 7 & 12 \\
\hline \multicolumn{2}{|c|}{ Grupo tratado: } \\
\hline Coelho 1 & 6 \\
\hline Coelho 2 & 4 \\
\hline Coelho 3 & 4 \\
\hline Coelho 4 & 4 \\
\hline Coelho 5 & 4 \\
\hline Coelho 6 & 5 \\
\hline Coelho 7 & 5 \\
\hline Coelho 8 & 4 \\
\hline Coelho 9 & 8 \\
\hline Coelho 10 & 5 \\
\hline
\end{tabular}


olhos que receberam ozonioterapia a média da graduação dos sinais clínicos foi de $4,90 \pm 1,29$. O teste $t$ das amostras estudadas evidencia diferença significante entre as duas amostras, utilizando um intervalo de confiança de $99 \%(\mathrm{P}<0,01)$.

A graduação dos sinais observados na análise histopatológica de todos os olhos está apresentada no quadro 2 . Todos os olhos estudados apresentaram reações inflamatórias agudas. No grupo controle, 5 (71\%) olhos apresentaram reações inflamatórias corneais moderadas; um olho apresentou reação inflamatória leve e outro apresentou reação inflamatória grave. Todos os sete olhos do grupo controle apresentaram reações inflamatórias graves na íris, no corpo ciliar, na coróide, no vítreo e na retina.

No grupo que recebeu terapia com ozônio, nenhuma córnea apresentou ao exame histopatológico reação inflamatória. Nove olhos apresentaram reação inflamatória moderada na íris e um olho apresentou reação inflamatória grave. Três olhos apresentaram reação inflamatória moderada no corpo ciliar e sete olhos apresentaram reação inflamatória grave. A coróide de 7 olhos apresentou reação inflamatória leve, em 2 olhos moderada e em 1 olho grave. Todos os 10 olhos do grupo tratado apresentaram reação inflamatória grave no vítreo. Nove olhos apresentaram reação inflamatória leve na retina e um olho apresentou reação inflamatória moderada.

A graduação dos sinais histopatológicos (Quadro 2) mostrou média de 17,00 $\pm 0,57$ para os olhos do grupo controle. A graduação para os olhos tratados com ozônio teve média de $10,20 \pm 1,30$. O teste $t$ com duas amostras mostrou diferença significativa entre as duas amostras com intervalo de confiança de $99 \%(\mathrm{P}<0,01)$.

\begin{tabular}{|c|c|}
\hline \multicolumn{2}{|c|}{ Grupo controle: } \\
\hline Coelho 1 & 16 \\
\hline Coelho 2 & 17 \\
\hline Coelho 3 & 17 \\
\hline Coelho 4 & 17 \\
\hline Coelho 5 & 17 \\
\hline Coelho 6 & 17 \\
\hline Coelho 7 & 18 \\
\hline \multicolumn{2}{|c|}{ Grupo tratado: } \\
\hline Coelho 1 & 13 \\
\hline Coelho 2 & 11 \\
\hline Coelho 3 & 11 \\
\hline Coelho 4 & 11 \\
\hline Coelho 5 & 9 \\
\hline Coelho 6 & 9 \\
\hline Coelho 7 & 10 \\
\hline Coelho 8 & 10 \\
\hline Coelho 9 & 9 \\
\hline Coelho 10 & 9 \\
\hline
\end{tabular}

\section{DISCUSSÃO}

O modelo experimental de endoftalmite utilizou o agente Staphylococcus epidermidis, por este ser o agente infeccioso mais comum nesta afecção. O tratamento com ozônio proposto não simulou as condições reais de infecção, nas quais o diagnóstico é realizado normalmente 24 horas ou mais após a contaminação. O objetivo da injeção imediata de ozônio diluído foi observar o comportamento e o curso da infecção nas primeiras 24 horas após a inoculação de alta concentração de bactérias com virulência comprovada, cultivadas no Laboratório de Microbiologia da Santa Casa de São Paulo, e depois comparar o modelo com grupo controle não tratado. A avaliação clínica da endoftalmite foi realizada a partir de graduações clínicas que levam em consideração as estruturas anteriores e posteriores do olho. A graduação histopatológica também seguiu esquema semelhante de graduação.

Em ambos os modelos houve intensa reação inflamatória do segmento posterior. No grupo controle houve reação grave da coróide, corpo ciliar, vítreo e retina; as córneas apresentaram reação moderada. No modelo tratado com ozônio diluído houve reação intensa do corpo ciliar, coróide e vítreo. Na retina destes olhos houve reação inflamatória leve na maior parte dos casos. Considerando as notas computadas tanto na avaliação clínica quanto na histopatológica, o modelo sem tratamento apresentou notas significativamente maiores (intervalo de confiança de $99 \%, \mathrm{P}<0,01$ ) do que o modelo tratado com ozônio. Grande parte desta diferença ocorreu em razão do pouco acometimento do segmento anterior do modelo tratado, em que houve menor reação inflamatória na íris e quase nenhuma reação inflamatória da córnea. A retina também mostrou menor acometimento inflamatório no grupo tratado.

Nossos resultados, apesar da pouca variação, desvio padrão baixo, e uma diferença significativa utilizando um intervalo de confiança alto, não permitem extrapolações diretas para a população humana. Os resultados encontrados fornecem indícios de que a injeção intravítrea de ozônio atuou de alguma forma na evolução da endoftalmite, resultando em graduações inflamatórias mais baixas. A solução de ozônio não foi capaz de erradicar a bactéria, já que a cultura da punção do humor vítreo foi positiva para todos os coelhos. Algumas hipóteses podem ser aventadas para explicar essa diferença:

- a injeção seqüencial da solução de ozônio reduziu bastante a carga bacteriana, o que levou à proliferação tardia da bactéria;

- propriedade antiinflamatória ou capacidade de estimulação imunológica local.

Estas duas hipóteses são apenas especulações e têm que ser comprovadas por meio de outras abordagens experimentais.

Este estudo mostrou que houve reação inflamatória ocular significativamente menor no modelo que recebeu ozonioterapia. Estes resultados podem ser comparados a outro estudo ${ }^{(9)}$, que encontrou melhora clínica em modelo experimental de endoftalmite tratado com ozônio. No entanto, os referidos autores não fizeram estudo histológico dos olhos estudados e não fizeram cultura do material intravítreo após o tratamento. 


\section{CONCLUSÃO}

Os resultados deste trabalho, ainda que baseados em amostragem pequena, estimulam a realização de outros trabalhos que mostrem a atuação do ozônio em cada estrutura ocular, observando toxicidade tecidual e reação inflamatória. Novas vias de administração, como a utilização direta do gás, e concentrações diferentes de ozônio devem ser verificadas. Além disso, sua eficácia deve ser posta à prova em comparações com outras formas de tratamento.

\section{ABSTRACT}

Purpose: To evaluate the anti-inflammatory and antimicrobial effect of intraocular ozone diluted in BSS on experimental Staphylococcus epidermidis endophthalmitis. Methods: We injected $0.1 \mathrm{ml}$ of $S$. epidermidis colonies $\left(10^{5}\right.$ colonies $\left./ \mathrm{ml}\right)$ to produce experimental endophthalmitis in the right eyes of $17 \mathrm{New}$ Zealand rabbits. Seven rabbits were assigned to a control group and received an intravitreal injection of $0.1 \mathrm{ml}$ BSS. Ten rabbits were treated with intravitreal injection of $0.1 \mathrm{ml}$ BSS-diluted ozone (2 ppm). Data were distributed according to clinical and histological findings after 24 hours, each rabbit receiving a score. Mean scores and standard deviations were compared using the two-sample $t$ test. Results: Mean clinical score for the control group was $11.14 \pm 1.04$. Mean clinical score for the treated group was $4.90 \pm 1.29$, which was significantly lower $(\mathrm{p}<0.01)$. Mean histological scores were, respectively, 17.00+ 0.57 and $10.20 \pm 1.30$ for the control group and the treated group. The histological scores were significantly lower for the treated group $(\mathrm{p}<0.01)$. All cultures in both control and ozone groups were positive after 24 hours of experiment. Conclusion: Treatment with diluted ozone significantly reduced the inflammatory reaction in our model of experimental endophthalmitis. This probably occurred due to a decrease in bacterial content after ozone injection. It is necessary to study other ozone concentrations in different experimental models in order to determine ozone efficacy with a higher precision.

Keywords: Ozone/therapeutic use; Endophthalmitis/chemically induced; Staphylococcus epidermidis; Saline solution, hypertonic; Ophthalmic solutions; Rabbits

\section{REFERÊNCIAS}

1. Ng EW, Samiy N, Ruoff KL, Cousins FV, Hooper DQ, Von Gunten S, Darnico DJ et al. Treatment of experimental Staphylococcus epidermidis endophthalmitis with oral trovafloxacin. Am J Ophthalmol. 1998;126(2):278-87.

2. Meredith TA, Aguilar HE, Miller MJ, Gardner SK, Trabelsi A, Wilson LA. Comparative treatment of experimental Staphylococcus epidermidis endophthalmitis. Arch Ophthalmol. 1990;108(6):857-60.

3. Aguilar HE, Meredith TA, Drews Q, Grossniklaus H; Sawant AD, Gardner S Comparative treatment of experimental Staphylococcus aureus endophthalmitis. Am J Ophthalmol. 1996;121(3):310-7.

4. Aldave AJ, Stein JD, Deramo VA, Shah GK, Fischer DH, Maguire JI. Treatment strategies for postoperative Propionibacterium acnes endophthalmitis Ophthalmology. 1999;6(12):2395-401. Commented on: Ophthalmology. 1999; 106(12):2237-8.

5. Ciulla TA. Update on acute and chronic endophthalmitis Ophthalmology. 1999; 106(12):2237-8. Commented on: Ophthalmology. 1999:106(12):2395-406.

6. Smith MA, Sorenson JA, D’aversa G, Mandelbaum S, Udeli I, Harrison W. Treatment of experimental methicillin-resistant Staphylococcus epidermidis endophthalmitis with intravitreal vancomycin and intravitreal dexamethasone. J Infect Dis. 1997;175(2):462-6.

7. Bocci V. Does ozone therapy normalize the cellular redox balance? Implications for therapy of human immunodeficiency virus infection and several other diseases. Med Hypotheses. 1996;46(2):150-4.

8. Bocci V. Autohaemotherapy after treatment of blood with ozone. A reappraisal. J Int Med Res. 1994;22(3):131-44.

9. Gundarova RA, Khoroshilova-Maslova IP, Bordiugova GG, Ilatovskaia LV, Lapina IM. Experimental validation of using ozonized physiological solutions in intraocular infection. Vestn Oftalmol. 1996;112(5):9-11.

10. Iuzhakov AM, Bykov VP, Ziurniaeva ID, Gogodze MG. New prospects in the treatment of intraocular infection. Vestn Oftalmol. 2000;116(2):20-2.

\section{CONGRESSO PAN-AMERICANO DE OFTALMOLOGIA}

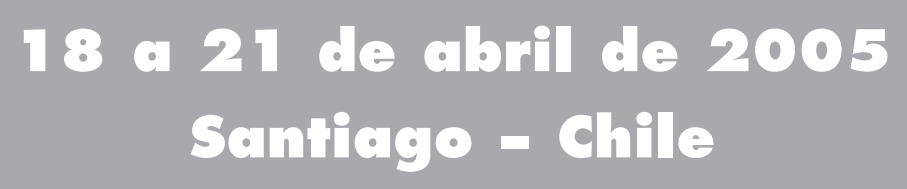

INFORMAC̣ÕES: E-mail: info@paao.org 